\title{
Developing responsible leadership through a 'pedagogy of challenge': an investigation into the impact of leadership education on teenagers
}

\author{
Rupert Higham ${ }^{1}$, Rob Freathy and Rupert Wegerif \\ Graduate School of Education, University of Exeter, UK
}

\begin{abstract}
This paper proposes a new model for understanding education through 'responsible leadership' - a term which draws on the models of distributed and authentic leadership and on a dialogic understanding of responsible action. It defines 'dispositions for learning' as different forms of the single quality of 'openness to learning'. A 'pedagogy of challenge' is proposed as a way of developing these dispositions. The model is tested through a small-scale investigation into the effect of a two-day leadership education course on five 14-year-old students which conforms to the proposed model. This suggests a link between the students' participation and their dispositions for learning; in addition, it suggests change in their attitude towards, and perceived performance in, their academic subjects over a four-month period.
\end{abstract}

Keywords: student leadership; dispositions for learning; pedagogy of challenge, responsible leadership

\section{Introduction}

In the UK education sector there is a strong emphasis on school leadership. Two examples among many are the formation of the National College of School Leadership (NCSL) in 2000 with a remit to promote high-quality leadership among school leaders, and the implementation in 2004 of the statutory National Standards for Headteachers outlining the key areas in which they are required to perform. In 2001 the NCSL also commissioned a course for developing leadership in students using the same key areas, which was devised by the University of the First Age and Community Service Volunteers, and which both organisations continue to deliver independently to date; it is one such course that forms the basis for the empirical study below. While there has since been a great deal of research into school leadership (C. Day et al., 2009, p.151), such student leadership courses have yet to receive sustained government funding or academic study; this may reflect an ambivalence at policy level towards the rights of students to examine and influence the structures and direction of their learning (Frost, 2008).

This article presents a model for understanding leadership education for students by defining and linking 'responsible leadership' and 'dispositions for learning' - and for developing them through a 'pedagogy of challenge'. The subsequent small-scale study of 5 teenage participants on a student leadership course, which conforms to our definitions of a pedagogy of challenge and responsible leadership, provides some initial support for this understanding of dispositions for learning as different kinds of 'openness to learning', which students see as beneficial to their self-understanding, their academic work and in their personal lives.

Education for responsible leadership

In this section we work towards a definition of 'responsible leadership' by drawing on elements from two approaches: distributed and authentic leadership. In the academic community and among training providers, the model of leadership has largely shifted away from a 'great individual' perspective, which

${ }^{1}$ Corresponding author. E-mail: r.j.higham@exeter.ac.uk 
focuses on the leading individuals' skills and characteristics towards the concept of 'distributed leadership': a quality of the relationships within a team with a shared goal (Spillane, 2004). By such definitions, the arts of leading and of following are intimately linked and the roles interchangeable, based on the situation. Day's distinction between leadership training, education and management is also useful here: leadership training is for individuals' present roles; leadership education, for individuals' future roles; and leadership management, for the present and future of an organisation (D. Day, 2001). Day sees the latter two functions as being equally important in the business context. However, applying this distinction to young people we can conclude that leadership education with a focus on individuals' skills and dispositions is the most important: here the context of school activities can be seen as 'safe and confidential settings' (Bolden et al., 2005 p.18) where students are allowed to experiment with different approaches without risk to the organisation - as would be the danger in the case of a business, for example. A distributed model can afford schools this flexibility, freedom and level of delegation.

While the concept of distributed leadership has received widespread support, it has also come under criticism for being too vague, and that its associations with valuing all members' contributions could be used to enforce the delegation of power within a rigid, top-down command structure (Hatcher, 2005; Strain, 2009; Woods \& Gronn, 2009). This may be of particular relevance to school contexts: while distributed leadership implies that students should be included in the decision-making process, efforts to elicit student voice may backfire if they discover that, having been given responsibility and taken pains to gather opinions and form plans, they have no real authority to institute changes. In drawing on distributed leadership theory, therefore, we have undertaken to be clear in our definitions below; we would also argue that the use of this theory in name alone to justify deceitful practices does not invalidate its use in genuinely inclusive, democratic contexts. This criticism, however, contains a kernel of truth: that just because leadership is distributed, it doesn't mean it is good - and since education should be a normative practice, a model for leadership education should contain a normative aspect.

In addition, distributed leadership theory focuses principally on the structure of a particular current organisation; this limits its utility with school-age children, where the focus is less on the role of students within their present learning institution and more about preparing them as individuals to work effectively in future contexts. We must therefore also look at leadership models which focus on individuals' personal development.

The concept of 'authentic leadership' has been proposed as a 'root construct underlying all positive forms of leadership and its development' (Avolio \& Gardner, 2005, p.316), which focuses not on structures or relations of power but on what makes leadership 'good' - grounded in the humanistic psychology of Rogers and Maslow. This normative approach establishes 'self-actualization' (p.319) as the foundation of leadership: acts of genuine leadership are thereby unique expressions of an agent's values through action; the results, they argue, are generally both persuasive and inspiring. This position has arisen in part in response to the perceived absence of genuine, forward-looking leadership arising from '...Wall Street's unquenchable thirst for quarterly profits' (Gardner, Avolio, Luthans, May, \& Walumbwa, 2005, p.344). The potentially problematic corollaries of this approach are that we must define examples of 'bad leadership' as not being genuine leadership at all, but perhaps as forms of deceit or tyranny; also, we must assume that the expression of people's uniqueness is always a good thing. In addition, there are many potential problems regarding identification and assessment of authentic behaviour (see Cooper, Terri, \& Schriesheim, 2005). While this approach is significantly different from structural definitions of leadership, it accords with a distinction in common usage. Sometimes when we call for leadership, we are referring to hierarchical models and authority roles, but at other times we refer to the need for values-in-action implied by 'authentic leadership'. This normative perspective seems particularly relevant to an educational context: leadership education for 1 
students need not be about teaching them to become Chief Executive Officers but instead it could be about enabling students to reflect their values through their actions, both individually and collectively.

Much of the literature on authentic leadership, however, emerges from a strongly businessoriented context with a strong focus on a company's bottom line (e.g. George, 2003); this may place constraints on the expression of values through action. In addition, examples given in this literature tend to be given as the individual heads of organisations (e.g. Shamir \& Eilam, 2005); this conforms quite closely to the structural model of 'charismatic leadership' and implies a less distributed approach. Finally, on an ontological level, this approach may also presume that there is a unique and pre-existing 'self' within us all, and that natural leaders are revealed as leaders through their authentic action. This may lead to a more determinist view of people's potential for leadership which is not the most useful in the context of youth education.

In response to the discussion of these two leadership theories, it could be argued that Heifetz et al.'s model of 'adaptive leadership' (Heifetz, Kania, \& Kramer, 2004) productively brings together elements of both. It demands that all stakeholders in an organisation are consulted in the face of complex challenges, and that the answer lies not in one person's approach but in a joint response - a core principle of distributed leadership. It also requires that all stakeholders are motivated into becoming actively and creatively involved in the problem-solving process - thereby drawing out their best, authentic contributions. However, this approach posits the systematic use of a particular set of tools, firmly orchestrated from the top, in order to bring about this process (Randall \& Coakley, 2007, p.328). This approach, therefore, does not allow the space for new ideas and approaches to emerge from a flatter hierarchical structure such as among student peers - or, arguably, among teachers.

Instead, we suggest another normative theory: 'responsible leadership'. This posits a dialogic ontology (Wegerif, 2007, p.27) in which good action emerges as an ethical response to an encounter with different people and perspectives that preserves the possibility of freedom of action for all parties within and outside the relevant group. The challenge offered by such encounters to member's beliefs, opinions and plans calls forth appropriate responses, reflecting their values while respecting the otherness of the other (Biesta, 2006). This model implies that there is no fixed underlying 'self' which is revealed through good action, since responses are always embedded in context; rather, agents' uniqueness is instantiated, and briefly visible, only in the moment of responsible action (Arendt, 2006, p.151). In common language it is not about people doing what they want to do, but about them doing what's there to be done in a way that is uniquely their own. It argues for a to shift from educationalists attempting to teach students about citizenship towards allowing students to learn how to be democratic citizens through providing genuine opportunities to act (e.g. Biesta \& Lawy, 2006). The focus of this study and of the course it examines, then, is not on abstract knowledge about leadership but on the cultivation of dispositional qualities: habits of mind and character that stimulate young people's intrinsic motivation for communication and action, and enable them to respond actively, insightfully and ethically to new and challenging situations.

Skills, habits and dispositions for learning

To be a good learner you have to be able. But if such capabilities are necessary, they are not of themselves sufficient. One has to be disposed to learn, ready and willing to take learning opportunities, as well as able. (Carr \& Claxton, 2002 p.10)

Schools tend to take a largely 'abilities-centric' approach to learning (Perkins, Tishman, Ritchhart, Donis, \& Andrade, 2000 p.269), placing far less emphasis on the motivational and habitual factors which underlie ability, generate intrinsic motivation and are transferable between learning contexts, and more on the expression of that ability in particular contexts - especially in relation to subject-based 
examinations. In the assessment of academic subjects, the factors of readiness and willingness can be largely bracketed out by the use of high-stakes examinations and assignments. These provide set times, places and deadlines for students' work and strong extrinsic motivation to succeed. Perkins and Tishman's studies have suggested that, given subsequent opportunities to utilise knowledge and skills acquired for formal examinations, students may neither be able to identify such opportunities, nor be willing to act upon them - and that these dispositional factors may therefore be more important than raw ability and subject knowledge, even in the case of academic tasks (Perkins \& Tishman, 2001). In this research we have termed these qualities 'dispositions for learning'.

Several attempts have been made to categorise the necessary dispositions for learning, the most prominent being Carr and Claxton's 'resilience, playfulness and reciprocity' (2002, p.9); however, they provide no compelling evidence to accept this list above the many others proposed in relevantly similar fields (Coffield, 2002). Indeed, Claxton accepts in later work that dispositions are in danger of being seen as 'a class of mental entities distinct from skills' while, unlike skills, they can neither be taught, nor tested, directly - since the manifestation of dispositions for learning must depend on individuals' subjective, personal engagement with specific contexts (Claxton, 2008). We propose that these dispositions for learning cannot be definitively listed and categorised objectively, as they can only be observed and interpreted subjectively within particular contexts; instead, they can all be understood as aspects of the single quality of openness. By openness we mean a propensity to remove, and continually reject, both self-imposed and socio-culturally imposed limits on responding to the call of the other: a readiness and willingness to engage in a genuinely open dialogue with difference and, where necessary, to step outside of previously held attitudes and beliefs in search of deeper understanding.

The model in Figure 1, therefore, proposes that 'responsible leadership' arises among students through appropriate learning actions and activities which, in turn, lead to the development of learning habits and skills, and then of dispositions for learning. Moving between these stages requires both appropriate contextual factors (such as 'self-understanding and reflection') and engagement in a dialogue with difference which calls students to respond personally and authentically - rather than in ways which are fixed and pre-determined. The model describes a gradual movement from the visibility, tangibility and physicality of learning actions and activities towards the invisibility and intangibility of 'responsible leadership' which, like other complex normative qualities such as wisdom, is describable only ostensively - that is, we can't define it, but we know it when we see it. The model further proposes that responsible leadership leads to new learning actions in response to the dialogue with difference, thereby perpetuating the learning cycle.

\section{Figure 1: A learning cycle for developing 'responsible leadership' among students}

\section{A pedagogy of challenge}

How could this model for 'responsible leadership' among students be realised? Through a study of the literature on leadership education and of democratic action in schools on the one hand, and of the methodologies of courses in leadership on the other, we propose a new interpretation of the key pedagogical elements for successful student leadership education - which we have sought to test in this research project.

For the purpose of explanation, let us assume that theories of teaching and learning can be divided into two categories: first, those that focus on what we might call 'accretional' or 'scaffolded' learning; secondly, and less commonly, those that focus on a pedagogy of 'interruption'(Biesta, 2006). Variations on accretional approaches dominate research on learning theory and accounts within teachers' training: these promote steady, planned progress with the learner being supported to take a series of consecutive steps towards more complex understanding and processes. The expectation is that 
we largely know what we want the learner to learn, and have strategies in place to enable this to happen. The latter type of learning, however, is one we are more familiar with in out-of-school, everyday contexts: being put in situations where people do not know what to do, feel challenged to the point of discomfort, and are forced to adapt, improvise and act in unaccustomed ways in order to find a solution. Examples might include trying to communicate with someone who doesn't speak the same language, or taking on responsibility for others after a family bereavement. While these are usually accidental experiences, they can provoke profound changes in understanding, motivations and abilities. Biesta argues that this can be adopted as a deliberate pedagogical approach: educators putting learners in situations where they are confronted with very different perspectives, beliefs and priorities - and thereby forced to reconsider, defend and adapt their own: '... it means that education ceases to be a process of giving, and instead becomes a process of asking, a process of asking difficult questions' (Biesta, 2006, p.85). By presenting personal, context-dependent challenges, an interruptive pedagogy calls forth personal responses that reflect individuals' personality and values - allowing them to build self-knowledge and confidence. An older term for this, derived from the traditional independent school ethos and picked up by Gosling in the context of leadership, is 'character' (Gosling, 2004); the term we propose for an interruptive pedagogy in the context of leadership education, founded in a dialogic ontology, is a pedagogy of challenge.

Dewey argues that our very environments can engage us in challenging dialogues 'by means of the action of the environment in calling out certain responses' (1966, p.11); for example, if a boy on an outward bound course is encouraged to climb a rock face for the first time, we might say that the environment 'calls for' attributes that he did not know he had. Similarly, we propose that education for responsible leadership should be challenging, communicative, emergent and active, and that a pedagogy of challenge provides the most effective way of creating spaces in which students can achieve relevant and personalised attitudinal and behavioural change. It provides encounters with difference which highlight relevant habits and skills for learning and provides the space for students to discuss and improve them; it challenges their self-imposed limits of what is possible, leading to changes in their dispositions for learning; it gives them the opportunity to act collectively in pursuit of aims they value. It should ask students to elicit and respond to the perspectives of others; put them in difficult situations in order to call out their unique responses, thereby building their confidence, selfknowledge and a positive attitude; allow them to make mistakes and to learn from them. In relation to such education, Bennis states '...there is no difference between becoming an effective leader and becoming a fully integrated human being' (1999, p.23). The following research seeks to test this proposal through the study of a course which uses such a pedagogy.

\section{Research design}

This study is based on data collected during a two-day leadership education course, which took 6013 18 year-old students out of their regular classrooms, and gave them a range of short activities, both group and individual, designed to develop through experience their awareness and practice of leadership qualities. The multi-ethnic, inner city secondary school had chosen the participants as potential leaders within the school community.

The data consists of extended interviews with five participants and ethnographic notes from the lead researcher, who attended the course as a facilitator alongside selected school staff, having received prior training from the provider. Three rounds of student interviews were conducted: just before the course, a week afterwards and finally four months later; this was to ensure that the object of the study was not just the immediate impact of the leadership course on participants, but also its impact over time as they integrated the lessons they had learnt into their everyday lives. Questions in all three rounds were similar, allowing for direct comparison across time. The period of time between interviews may have been too short for this to be classified 'longitudinal research' in the traditional sense (Saldaña, 
2003, p.6);. However, even over these four months there were significant changes both in the school and in the students' personal lives - as is inevitable for students at a stage of fast personal and intellectual development. Therefore, while it would not be appropriate on the basis of this time span to suggest that we can determine the 'end product' of the course in terms of its effect on students - or a 'from-to' approach, we can nevertheless build a picture of its perceived effect on them, among other factors, up to that point - or a 'from-through' approach (ibid., p.8).

The interviews were recorded, transcribed and coded for analysis using computer software; the coding was derived through several iterative cycles, allowing the data to be analysed both longitudinally in reference to participants' narratives of change, and laterally to identify patterns between participants at the different stages of interview. These codes were neither pre-determined by our theoretical assumptions, nor were they emerged wholly from the data as in a pure grounded theory approach (Creswell, 2007, p.66). Instead, they resulted from a dialogue between the two, allowing critical distance and the opportunity to be surprised and challenged by the data. The main titles below are the research questions; the subtitles reflect some of the themes that emerged through the coding process.

\section{Results}

In what ways are the students challenged on the leadership course?

Being "outside your comfort zone"

At the start of the leadership education course, the facilitator asked all participants to spend as much time as they dared outside their 'comfort zone'. This was a frequently repeated, central metaphor - and one which was widely appropriated by the interviewees in both the second and third interviews:

...since that two day course I think all of us have actually come out of our comfort zone. Every single one of us, we talk to each other more now. I've talked to people I don't even know before....

Student E, int.2

While all the students recognised this as a good thing after the event, one noted that it had often been challenging, even scary, at the time:

...when we were told to do the activity I'm not used to someone telling me to do this - I felt really like, scared... I didn't know how other people would react to it.

Student A, int.2

Student A suggested that the different nature of the activities from what they usually do in the classroom was in itself disconcerting; it made her self-conscious because she did not know what to expect, calling on her to respond thoughtfully and deliberately with others without prior expectations which lead to predictable, reactive behaviour.

\section{Working outside year and friendship groups}

At the start and throughout, the course facilitator encouraged students to take the initiative themselves to form groups with people of different ages, ethnicities and backgrounds. The course leader also asked them to keep working with different people in each activity. All interviewees cited this as a valuable experience - for several, the most valuable - that they gained from the course, even if it was challenging for some at first. A frequently mentioned aspect of this was working with older students:

I: How did you find working with people who weren't your own age?

C: I think that was quite good as well, because the variety of age, they sort of like, had different understandings of the things you had, and you could like, take those

Student C, int.2 
understandings and apply them to your understanding. With two different understandings you can find a mutual understanding of something, or if it's just like, you didn't know what it was you could, ask - they'd tell you and they'd help you sort of... improve. Like kind of an improved learning... environment.

Student $\mathrm{C}$ here reflects a movement shared by other students from a sense of vulnerability and fear of ridicule, to excitement, satisfaction and a sense growth. The action of entering into open dialogues with new people and realising that they could learn from them was an empowering experience which engendered trust and confidence.

How do students' dispositions for learning change?

\section{Confidence}

All the students talked about having grown in confidence - which had had a demonstrable impact over the subsequent months in their academic work, or in their wider lives, or often both. For many, this was the most valuable lesson they felt they had learned.

Student B suggested in the first interview that she needs others to draw her out to improve her learning, but lacks confidence take the initiative:

\section{I: ...when do you think you learn best?}

B: When people ask me questions.

I: ... What do you think that does for you, being in conversation with someone or having people ask you questions?

B: It helps me to speak out louder in class.

I: Is it because normally you wouldn't speak?

B: I'll just get on with my work by myself.

Student B, int. 1 herself:

By the second interview, she demonstrated a new willingness to show initiative and belief in

I: Do you think you will act differently in the school community as a result of the course?

B: Yeah - I think I'll speak more and talk to people I don't usually talk to.

I: And why will you do that?

Student B, int.2

B: Because I'm gonna be confident and meet new people.

This determination seemed to have borne results by the time of the third interview:

I: How would you say that your approach has changed or your understanding has changed?

B: Cause like, now I put my hand up in class.

I: Right, and why didn't you do that before?

B: I don't think I was that confident.

I: OK, and what difference has it made, asking questions in class?

Student B, int.3

B: It makes me feel open.

I: That's interesting - can you explain that a little more?

B: Like... I've got control over myself.

This sequence of quotations suggests that Student B had determined to be more confident, and through doing so helped bring about the sort of classroom dialogue which she believed would help her learn. Furthermore, she also had a greater sense of her own agency - she recognised her greater 'control over herself'. The challenging experiences of the course were remembered by all five students as a watershed - marking a shift from more cautious, defensive habits towards open, confident engagement with others.

\section{Learning from multiple perspectives}


Another point of agreement among all interviewees was that they had come to appreciate the value of a range of points of view - especially from people outside their normal friendship groups - in forming their own opinions and making joint decisions. Most activities demanded they they actively seek the opinions of all group members, and that those groups should be as diverse as possible. Student D stated in the first interview that he believed that learning in the classroom is a partnership between the teacher and the individual student; his third interview, however, suggested a change of emphasis:

D: I think I've acted a bit differently because before I would stick with a few friends and just hang around with them - but now I just go and talk to different people I never knew...

I: And do you feel that you've gained from that? To speak with a wider group of people?

Student D, int.3

D: Yes. Every human is not the same. Everyone's got different points of view. I like to see everyone's points of view and then make a judgement.

Here he described actively seeking others' opinions - not just to benefit his own work but also for his own interest and development. The idea of listening to other ideas so he can 'make a judgement' suggests a higher order of learning than getting help understanding the question from someone else, or sharing right answers. Instead, he now found the contrast of others' different views against his own to be intrinsically motivating; he had come to appreciate challenges to his opinions as contributing to his broader development rather than looking only to build on his subject-based knowledge.

Together, students' comments suggested that they had learned to seek out and make use of a range of perspectives in both their academic and personal development - and that they saw this as an ethical process that led them to place greater value on others because of, rather than in spite of, their differences.

\section{Listening}

The leadership course focused explicitly on the skills of listening to others as the basis of good teamwork. On several occasions, course participants were asked to come to decisions as equals in their groups. The quotation below demonstrates how Student C saw these practical opportunities as developing his personal skills:

$\mathrm{C}$ : Because like, in our group, there was quite a lot of debating and arguing over the ideas and which bid to go for and things like that. And I was more like saying, 'what if we do this, and add his ideas to this, and mix them together - then you'd get a better idea out of both'. And I was like, support, really.

I: And can you think how, before the course, how might have you been differently in that situation?

C: Before the course I probably would have just added my idea to the argument, and then people would have stood their ground - and it might have got out of control.

Here he cites a radical change from older habits in working with others, a new-found sensitivity to their thoughts and feelings. In his third interview, however, he focused on what he had learned about himself and his plans for the future, making little mention of other students. It may be that Student C's discernment of opportunities to develop these skills on the course did not transfer strongly into subsequent classroom experience; it may also be that a return to a regular classroom routine had not provided him with such clear and memorable opportunities as arose on the course. This tendency to talk less about listening and empathising in the third interview was pronounced among almost all the students. Student E suggested that there is much to learn from listening to others - but as a personal interest outside classroom learning. Taken together the students interviewed seemed to recognise the utility of these skills in completing the challenges set during the course, and expressed a feeling of excitement through having done so; however, the final interviews suggested that they had not retained a 
sense of these skills as vital to their academic learning, but rather as having contributed more broadly to their personal development and wider roles outside the classroom. As the interviews contained no test of listening skills, they provided no evidence regarding whether, and the extent to which, these skills were retained.

\section{Response to pressure of examinations}

When asked by the researcher what most motivated them in their learning, all students put 'good grades' as either their first or second most important factor in all three interviews. The desire and perceived need to do well in exams was evident throughout the rest of the first interviews:

The most challenging thing about school life is probably doing exams, and kind of being a part in it because that just... the main thing in school: exams. You learn and then you do your exams.

Student E, int. 1

By contrast, none mentioned exams in the second interviews; this may well be due to the recent vivid experiences of the course, and by the fact that in the penultimate week of the school year, these Year 9 students had no exams on the horizon. However, the third round of interviews took place when they were preparing for, or had just had, GCSE exams. Student D, when asked what he had done in the school community as a result of the leadership training since the course, replied:

I think we didn't do quite much as we have to prepare for our GCSE tests, which were quite hard... we didn't really have time to do that much - but I think we organised - never did it, but we planned - the leadership workshop for Year 7 who just came.

Student D, int.3

He and others suggested that they had been able to do less leadership activity than they would have liked within the school community subsequently. In addition, there is evidence that students felt that the cooperative, communicative approaches to learning they developed on the course would be inappropriate in many of their lessons. However, Student B, having said in the first interview that exams were the most challenging aspect of school, and that she was afraid of letting herself down in them, said in the third interview that she felt 'prepared' and 'confident' for her exams - a new-found confidence she attributed to attending the course.

While there is evidence that the students chose to adopt a mindset of challenge after the course in response to upcoming examinations as a way of tackling them positively, they also recognised that they required of them a substantially different approach from the one they took on the course. Consequently, there is a clear shift between the second and third interviews from cooperative, community-focused activity towards individual, examination-focused activity.

Does the leadership course influence the students' perceived academic performance?

All five students said that they felt the course had made a difference to their academic performance; three cited specific subjects in which they believed they had improved, while two cited skills and habits they have learned which they believed allowed them to work better across the board.

The clearest example of perceived progress came from Student C, who in the first interview related that the effort he makes in English leads only to frustration:

I: OK what about English, then? What is it about English that's tricky for you?

C: Wording, like, how you word things, 'cause that's quite important. 'Cause if you don't word it right, you might give the wrong impression and come across wrong, and then that can lose you marks and grades and things like that.

I: Right. Is that because... there isn't a clear answer, as it were?

C: No - there's a clear answer - it's just I can't find how to put it.

Student C, int.1 
Student $\mathrm{C}$, who elsewhere stated that he gains satisfaction from solving puzzles and finding the 'right' answer, seemed to struggle in a subject in which stating a case, rather than finding the correct solution, is required. After the course, he acknowledged the value of sharing perspectives as potentially beneficial to him in this regard:

I think the fact that you're doing the tasks with other people, I think that's going to help slightly in English, because in English when you do literature and things like that you have to know different points of view, take them into consideration and things like that if you have a debate or a report or things like that.... And I think the course would help me with that.

Student C, int.2

When asked in the third interview whether his change of perspective regarding English had led to any lasting change of approach, he replied:

C: Yeah, probably in English I've been trying harder to understand, like, different terms and how to put them into essays....

I: Do you think it's led to any improvement in your performance?

C: Yeah. Before I struggled to write a paragraph, but now it just flows out... I'm struggling to fit it into a paragraph.

This final extract suggests a significant, liberating sense of progress - but it does not link neatly with Student C's new-found appreciation of multiple perspectives and teamwork in interview 2. However, when the medium of assessment is essay-writing, such collaboration is more difficult - even forbidden. Nonetheless, he demonstrated having deliberately attempted to improve his English, and having found a way which used his facility to solve problems - using the 'tools' of technical terminology to provide a productive new perspective on the material. In addition, it suggested increased resilience and innovation in the face of challenge; in the first interview, by contrast, he stated that he did not think he could further improve his academic performance, even in the subjects like English where he was struggling.

As well as progress in specific subjects, students talked about broader changes in approach and behaviour which impacted on their academic performance. For example, Student D found he was able to gain from the support and perspectives of students he had not previously known, while Student B felt that her choosing to get more engaged in classroom dialogue had benefited her grades.

The skills and working methods required of them in the classroom and examination hall are markedly different from those developed through the dialogue-led, problem-solving approach of the course. However, when drawn upon to describe their experiences in the classroom in the second and third interviews, all revealed significant changes in attitude and approach to their studies since the course - which they believed had brought about significant improvement.

\section{Discussion and Conclusion}

These results provide evidence of these five students' increased willingness to communicate, to value others' opinions, to contributions to shared activity, and to participate in school and community life. In addition, there is also a sense of that their perceived self-knowledge has increased, and that these lessons have been reinforced through their subsequent experience. Taken together, the results suggest significant development in the students' dispositions for learning as a result of the leadership course. They internalised concepts such as 'working outside your comfort zone' and applied them productively to situations they had found difficult before, both inside and outside the classroom. There is even significant evidence of perceived personal and moral development as a result of their experiences during and following the course. These are the main foci of professional leadership development programmes; they are also essential elements in building 'character' in young people, preparing them to face future challenges intelligently, ethically and with confidence. Additionally, the students clearly 9 
believed that their academic performance had or would improve as a result of the steps they had taken following their experiences on the course. In contrast, there was also evidence of a lack of subsequent opportunities for students to practice their newfound skills and to continue to develop their dispositions for learning through practical opportunities for action.

The students' descriptions of their attitudinal change - such as having the confidence to ask questions, seeking and incorporating others' perspectives into their thinking, relishing working with students very different to themselves, and looking for new ways to appreciate and approach their academic work - appear to support our definition above of 'dispositions for learning' as forms of openness, rather than as a set of distinct and discrete qualities.

Also, these results suggest that the key to the course's success was its focus on challenge: it was the students' memories of difficult situations they were placed in, and their resolution, that were strongest, and which they understood as having precipitated changes in their understanding. This was partly due to the unfamiliar activities undertaken, and partly due to their unfamiliar environment. Students found that working with people they did not know exposed them to the possibility of unforeseen responses; they were used to working with the same students in predictable classroom scenarios; by contrast, they were called upon to find unique solutions drawing on a range of perspectives - a process they found surprising and liberating.

Finally, these results suggests that students can demonstrate responsible leadership when given enough support in building the appropriate skills and habits for learning, and space for their dispositions for learning to develop. On the other hand, these results draw attention to the limiting factors of a school context still ruled by accountability to examination performance. A limitation of the methodology was that there was no way of gauging whether skills developed on the course but not subsequently used had been retained. While these students claim to have retained many personal insights and habits they gained on the course, they can only continue to demonstrate responsible leadership in their learning and in their wider communities when offered continuing opportunities and support for meaningful action.

While the focus of this study was firmly on student leadership, the fact that the course studied was modelled on the same key principles as the National Preparatory Qualification for Headship prompts further questions for research: for example, would the apparent success of this course have been improved or undermined by a far more structured, evidence-based approach such as on the NPQH? Regarding this short course, the evidence suggests that it was the affordance of challenging, open-ended opportunities for taking responsibility as part of diverse groups, rather than course content per se, which was the spur for personal development and leadership capacity. Would this apply in relation to adult leadership in schools?

This small-scale study supports the approach of a pedagogy of challenge in developing students' dispositions for learning. It also offers some support for the proposed model for understanding education for responsible leadership. However, this research was limited by the small number of participants studied, its restriction to a single course, and by a lack of objective indicators to corroborate or question the students' self-perception. There is now an opportunity for broader research looking at a range of student leadership courses, including those in outdoor and community contexts, and looking at their longer-term effects on student progress, by looking at academic performance levels and through the use of quantitative psychological instruments. Such an approach could both deepen our understanding of students' understanding of how they respond to the challenges of leadership, and possibly demonstrate tangible benefits of this approach that will accord with the priorities of policymakers.

\section{Acknowledgements}

The authors gratefully acknowledge the support of The Challenger Trust in supporting this research project. 


\section{References}

Arendt, H. (2006). Between Past and Future. London: Penguin.

Avolio, B. J., \& Gardner, W. L. (2005). Authentic leadership development: Getting to the root of positive forms of leadership. The Leadership Quarterly, 16(3), 315-338.

Bennis, W. (1999). The leadership advantage. Leader to leader, 12, 18-23.

Biesta, G. (2006). Beyond learning: Democratic education for a human future. Boulder, CO: Paradigm Publishers.

Biesta, G., \& Lawy, R. (2006). From teaching citizenship to learning democracy: overcoming individualism in research, policy and practice. Cambridge Journal of Education, 36(1), 63-79.

Bolden, R., Case, P., Gosling, J., Hooper, A., Kinsella, K., Ladkin, D., et al. (2005). What is Leadership Development? (No. 2). Exeter: Leadership South West.

Carr, M., \& Claxton, G. (2002). Tracking the Development of Learning Dispositions. Assessment in Education: Principles, Policy \& Practice, 9(1), 9-37.

Claxton, G. (2008). Cultivating Positive Learning Dispositions. In H. Daniels, H. Lauder \& J. Porter (Eds.), Routledge Companion to Education. London: Routledge.

Coffield, F. (2002). Skills for the Future: I've got a little list. Assessment in Education: Principles, Policy \& Practice, 9(1), 39-43.

Cooper, C. D., Terri, A. S., \& Schriesheim, C. A. (2005). Looking forward but learning from our past: Potential challenges to developing authentic leadership theory and authentic leaders. The Leadership Quarterly, 16(3), 475-493.

Creswell, J. (2007). Qualitative inquiry and research design: Choosing among five approaches (2 ed.). Thousand Oaks, CA: Sage.

Day, C., Sammons, P., Hopkins, D., Harris, A., Leithwood, K., Gu, Q., et al. (2009). The Impact of School Leadership on Pupil Outcomes: Final Report: DCSF.

Day, D. (2001). Leadership Development: a review in context. The Leadership Quarterly, 11(4), 581613.

Dewey, J. (1966). Democracy and Education. New York: The Free Press.

Frost, R. (2008). Developing student participation, research and leadership: the HCD Student Partnership. School Leadership \& Management, 28(4), 353-368.

Gardner, W. L., Avolio, B. J., Luthans, F., May, D. R., \& Walumbwa, F. (2005). "Can you see the real me?" A self-based model of authentic leader and follower development. The Leadership Quarterly, 16(3), 343-372.

George, W. (2003). Authentic leadership: Rediscovering the secrets to creating lasting value. San Francisco: Jossey-Bass.

Gosling, J. (2004). Leadership Development in Management Education. Business Leadership Review, 1(1). Retrieved from www.mbaworld.com/blrissues/article1.htm

Hatcher, R. (2005). The distribution of leadership and power in schools. British Journal of Sociology of Education, 26(2), 253-267.

Heifetz, R., Kania, J., \& Kramer, M. (2004). Leading boldly. Stanford Social Innovation Review, 2(3), 2032.

Perkins, D., \& Tishman, S. (2001). Dispositional Aspects of Intelligence. In J. M. Collis \& S. Messick (Eds.), Intelligence and personality: bridging the gap in theory and measurement. Mahwah, NJ: Lawrence Erlbaum Associates. 
Perkins, D., Tishman, S., Ritchhart, R., Donis, K., \& Andrade, A. (2000). Intelligence in the Wild: A Dispositional View of Intellectual Traits. Educational Psychology Review, 12(3), 269-293.

Randall, L. M., \& Coakley, L. A. (2007). Applying adaptive leadership to successful change initiatives in academia. Leadership and Organization Development Journal, 28(4), 325-335.

Saldaña, J. (2003). Longitudinal Qualitative Research. Walnut Creek, CA: Altamira Press.

Shamir, B., \& Eilam, G. (2005). "What's your story?": A life3-stories approach to authentic leadership development. The Leadership Quarterly, 16(3), 315-338.

Spillane, J. (2004). Distributed Leadership: What's all the hoopla? Retrieved from hub.mspnet.org/index.cfm/9902

Strain, M. (2009). Some Ethical and Cultural Implications of the Leadership 'Turn' in Education. Educational Management Administration \& Leadership, 37(1), 67-84.

Wegerif, R. (2007). Dialogic Education and Technology. New York: Springer.

Woods, P., \& Gronn, P. (2009). Nurturing Democracy. Educational Management Administration \& Leadership, 37(4), 430-451. 